Original Research Paper

\title{
Synthesis and Characterization of Ink (Carbon)- Perovskite/Polyaniline Ternary Composite Electrode for Sodium Chloride Separation
}

\author{
Savita Dixit and Sandhya Pal \\ Maulana Azad National Institute of Technology, Bhopal, India
}

Article history

Received: 18-02-2015

Revised: 07-05-2015

Accepted: 12-05-2015

Corresponding Author

Savita Dixit

Maulana Azad National Institute of Technology, Bhopal, India

Tel:+91-755-4051653

Fax: +91-755- 2670562

Email: savitadixit1@yahoo.com

\begin{abstract}
We reported the synthesis of ink-perovskite/Polyaniline composite electrode material for the separation of sodium chloride solution. These electrode materials are prepared by in situ polymerization process of aniline in the presence of perovskite ceramic material with carbon catalyst surface. This material is having the highest conductivity as a cathode material, environmentally benign and low cost material. The structure and morphological properties of prepared ternary composites are characterized by Fourier transform infrared, X-ray diffraction, SEM and TGA. The electrochemical properties are also investigated using four probe method and cyclicvoltametry method. Electrochemical measurement shows that the conductivity of ternary composites is $128 \mathrm{Scm}^{-1}$. Resulting composites are promising cathode material for low power consuming electrolysis process of sodium chloride solution.
\end{abstract}

Keyword: Polyaniline, Perovskite, Carbon (Ink), Electrode, Electrodilysis

\section{Introduction}

Nowadays, conducting polymers has been paid much attention due to their wide applications in many fields such as Electromagnetic (EM) interference shield, chemical sensors, electrodes, electro ceramic devices, microwave absorption coating materials, electro catalyst in electrolysis and fuel cell etc. (Cui et al., 2013). The electro dialysis applications include desalination of water (Kariduraganavar et al., 2006; Kalogirou, 2005), production of acids and bases (Tongwen, 2002; Faverjon et al., 2006) production of organic acids (Huang et al., 2007), recovery of metal ions (Santarosa et al., 2002; Ahmed et al., 2002), desalination of cheese whey (Bazinet, 2004), etc. Current efficiency and power requirements are two main factors in the clear alkali electrolysis experiment. In the Chloralkali cell, chlorine ions liberates the electrons to form chlorine gas at the anode and at the cathode; water takes up these electrons releasing hydrogen gas and hydroxyl ions. The amount of electric energy needed for driving the electrode reaction depends mainly on the type of the electrolytic cell with their respective thermodynamic decomposition potential difference
( $\triangle E$ ) (Furuya and Aikawa, 2000). During the Hydrogen Evolution Reaction (HER) a high voltage input, i.e., $1.23 \mathrm{~V}$ more than the Oxygen Reduction Reaction (ORR) is required and thus, results in an inefficient means of energy consumption for producing the desired and undesired products. The total cell voltage applied, leading to increased energy efficiency for a Chloralkali cell can therefore be realized by reducing the thermodynamic decomposition potential difference $(\Delta \mathrm{E})$ between Hydrogen Evolution Reaction (HER) and the Oxygen Reduction Reaction (ORR) or the oxygenconsuming cathode.

In the electro dialysis experiment, suitable electro catalysts can be used as the cathode. Oxygen reduction electrodes, containing non-noble metal catalysts supported on high surface area carbon and wet-proofed with PTFE were proved to be effective (Kiros and Bursell, 2008). The impact of electro catalysts to bring about high activity, i.e., high current densities at lower potentials and attain stable performances without significant degradation over a period of time is of utmost importance for gas diffusion electrodes. Many inexpensive, non-noble metal catalysts we know accelerate the rate of the reaction to a substantial level. 
Metal oxides, perovskite and paralyzed N4-organic complexes have been found to be among the costeffective and active electro catalysts for ORR in alkaline electrolytes (Tributsch et al., 2008; Faubert et al., 1998; Bezerra et al., 2008; Zhong et al., 2006; Wang, 2005). Experiments have revealed that modes of catalyst preparation, selection of high surface area carbons together with chemical, physical as well as thermal pretreatments have a profound effect on the overall outcome on the cathodic reactions of these materials.

The electrically conductive nature of the Polyaniline (PANI) family has been well known (Ogura et al., 1998). Polyaniline (PANI) was widely studied due to its unique stability, conductivity and low cost (Phadnis and Joshi, 2007). The magnetism, conductivity and other physical properties of PANI can be improved by doping with metal oxide (Strathmann, 2005; Sarraco, 2003; Strathmann, 2004; Noble and Stern, 1995). Among the electrically conducting polymers this family of compounds attracted intense attention due to its environmental stability, ease of synthesis, exciting electrochemical, optical and electrical properties. It is found that a metal salt, a nitrogen donor and a carbon support are required to prepare cheaper oxygen reduction active catalysts (Ye and Vijh, 2003). Perovskite materials exhibit special properties from the application point of view. These compounds are used as catalyst electrodes in fuel cells (Matthew and Swartz, 2004; Bastidas et al., 2006; Lurdes et al., 2001) and in oxygen production by air separation (Kharton et al., 1999; Wang et al., 2004). Thus the perovskite exhibit appreciable oxygen ionic and electronic conductivity, have become of great interest as a potential economical, clean and efficient means to produce pure oxygen. So perovskite is used as a support for loading ORR catalyst synthesized in the electrolysis of sodium chloride cathode.

In the present work, we studied the morphology and electrochemical properties of Ink-perovskite/polyaniline ternary composite material. Polyaniline was formed by in situ polymerization process and electrode material prepared by a solid state process. Conducting material was characterized by means of four probes and cyclicVoltammetry method and morphological properties are characterized by Fourier transform infrared, X-ray diffraction, SEM and TGA.

\section{Material and Methods}

\section{Experimental}

Chemicals Aniline (Sdfine), HC1 (Sdfine), Ammonium per sulfate, Fluka), aqueous ammonia solution (Fluka), isopropyl alcohol (Merck), Lanthanum nitrate (Loba), Strontium nitrate (Loba), cobaltousnitrate
(Loba), ferric nitrate (Fluka), EDTA (Sdfine), NH4OH (Merck) and carbon (Sdfine) were used. Double distilled water was employed.

\section{Preparation of Ternary Composite Material}

\section{Preparation of Perovskite}

Perovskite is prepared following the EthyleneDiamine-Tetra-Acitic acid (EDTA) method (Tsiakaras et al., 1998). Different nitrates are mixed in water in the given proportion in separate beakers. Lanthanum nitrate $(6.46 \mathrm{~g}) 16 \mathrm{~mL}$ of water, Strontium nitrate $(20.0 \mathrm{~g})$ is mixed with $40 \mathrm{~mL}$ water, cobaltous nitrate $(10.24 \mathrm{~g})$ in $20 \mathrm{~mL}$ of water and ferric nitrate $(60.0 \mathrm{~g})$ in $110 \mathrm{~mL}$ of water is taken and then mixed with Ethylene-Diamine-Tetra-Acitic acid (EDTA) (31.05 g) mixed in $500 \mathrm{~mL}$ of water. The $\mathrm{pH}$ is maintained at 8.0 exactly using $\mathrm{NH} 4 \mathrm{OH}$ and the mixture is stirred vigorously for $12 \mathrm{~h}$ at a temperature of $55^{\circ} \mathrm{C}$. The precipitate formed is then filtered, dried and milled to get the perovskite powder.

\section{Preparation of Poly Aniline}

Aniline (9.313 g, $0.100 \mathrm{~mol})$ was added to $\mathrm{HCl}$, solution $(100 \mathrm{~g}, 1.0 \mathrm{M})$ and the $\mathrm{pH}$ adjusted to +1.0 by the further addition of a few drops of HCI. Ammonium per sulfate $(28.52 \mathrm{~g}, 0.125 \mathrm{moL})$ was dissolved in distilled water $(51.5 \mathrm{~g})$ and added to the reaction solution which was being stored at room temperature. After $30 \mathrm{~min}$ the precipitate formed was recovered by filtration, washed with distilled water (200 $\mathrm{mL})$, deprotonated by stirring for $24 \mathrm{~h}$ in aqueous ammonia solution $(100 \mathrm{~mL}, 33 \% \mathrm{w} / \mathrm{v})$, refiltered and washed with water $(200 \mathrm{~mL})$ then with isopropyl alcohol $(200 \mathrm{~mL})$ and finally dried under vacuum at $60^{\circ} \mathrm{C}$ for $24 \mathrm{~h}$ to give $8.46 \mathrm{~g}$ of a purple powder (Adams et al., 1996).

\section{Preparation of Catalyst Ink}

The direct adsorption procedure is used to load the carbon with the electro catalyst. Electro catalyst polyaniline and perovskite $(1 \mathrm{~g})$ obtained from steps 2.1 and 2.2 is mixed with carbon $(3 \mathrm{~g})$ in $25 \mathrm{~mL}$ of water to give a $25 \%$ loading. It is then sonicated for $4 \mathrm{~h}$, dried at $750^{\circ} \mathrm{C}$ and then heated at $900^{\circ} \mathrm{C}$ under $\mathrm{N}_{2}$ atmosphere.

\section{Preparation of Porous Electrodes}

The mixture is cast over a metal (stainless steel, copper, nickel coated copper) mesh and compressed by the use of steel plates on both sides. It is then sintered at $360^{\circ} \mathrm{C}$ for $1 \mathrm{~h}$. The electrode is then loaded with catalyst ink (preparation given in Fig. 1) and heat treated at $900^{\circ} \mathrm{C}$ for $1 \mathrm{~h}$ under nitrogen atmosphere. The image of porous electrode is given in Fig. 2. 


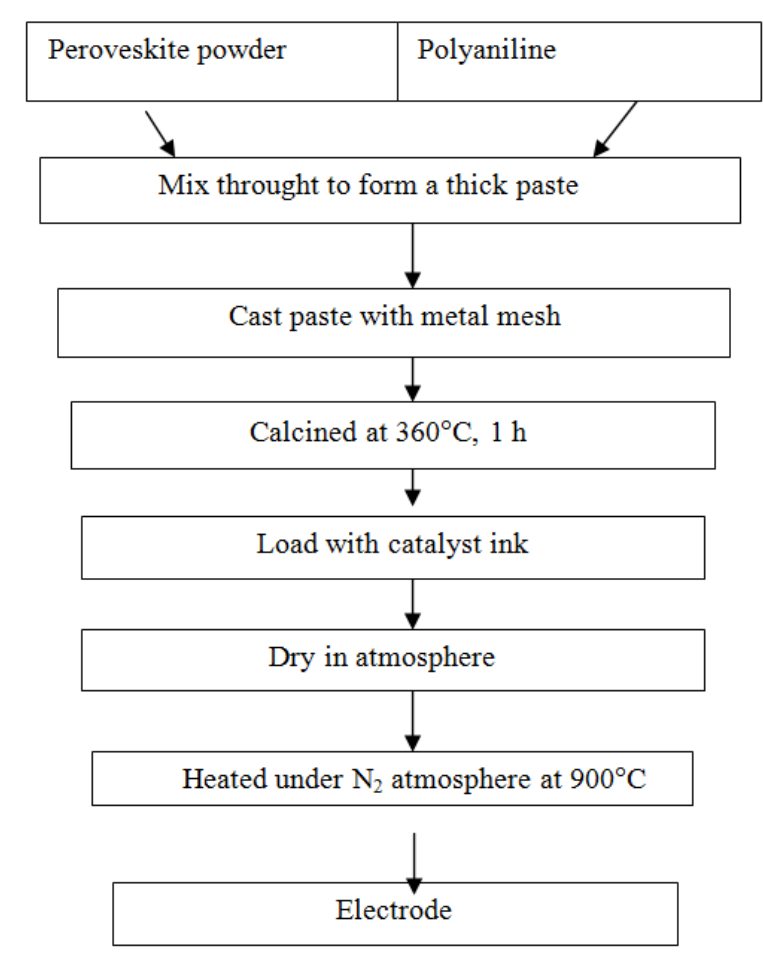

Fig. 1. Prepration of electrode material

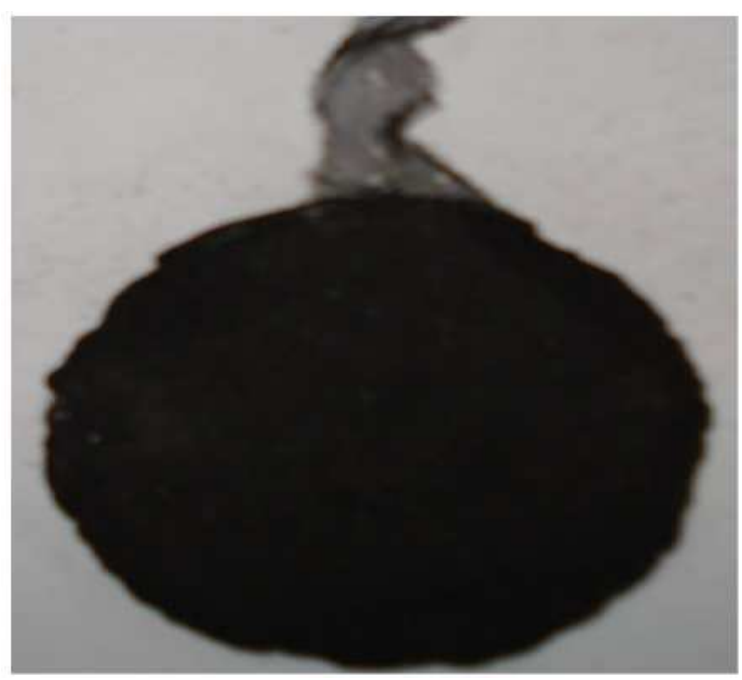

Fig. 2. Image of electrode

\section{Characterizations of the Ink Perovskite/Polyaniline Composite Electrode}

The FT-IR spectra wear recorded on a bruker FTIR(Vertex-70). Spectrophotometer in the range of 4,000$500 \mathrm{~cm}^{-1}$ resolution with $\mathrm{KBr}$ pellets at room temperature. The XRD pattern measurement Seifert XRD Debyeflex 2002 was employed to study the crystal structures of the composite electrode. The surface morphology and nanostructure of the electrode were recorded on FEI, Quanta $200 \mathrm{HV}$ spectrophotometer. The electrical conductivity of the composite, pressed into pellet under $15 \mathrm{MPa}$ at room temperature, was measured by a four point probe technique using a programmable Direct Current (DC) voltage/current detector and cyclic voltammeter analysis performed by the gamrey potentiostate analyser with scane rate of $10 \mathrm{~V} / \mathrm{s}$. Thermal Gravimetric Analysis (TGA) was performed on a PerkinElmer Pyris Diamond analyzer with a heating rate of $10^{\circ} \mathrm{C} \mathrm{min}^{-1}$ in $\mathrm{N}_{2}$ atmosphere.

\section{Results and Discussion}

\section{FTIR Spectra}

FTIR spectra is used to analyze the functional groups, nature of bonding and the chemical structure of the compound Fig. 3 shows the FTIR spectra of catalytic Ink perovskite/polyaniline ternary composites recorded in the range of 4,000 to $500 \mathrm{~cm}^{-1}$ at ambient temperature, respectively. Polyaniline has the characteristic peaks observed at1, 578 and 1,482 which can be ascribed to $\mathrm{C}$ $=\mathrm{C}$ and $\mathrm{C}=\mathrm{N}$ stretching vibration of quinoid and benzene ring, which indicate the oxidized stage of the PANI. The peaks at 1,305 and 1,360 correspond to the $\mathrm{C}=\mathrm{N}$ and $\mathrm{C}-\mathrm{N}$ stretching band of a secondary aromatic amines, while the peaks at $1,198 \mathrm{~cm}^{-1}$ are due to the in plane bending vibration mode of $\mathrm{C}-\mathrm{H}$, which is associated with high electrical conductivity and high degree of electron delocalization of polyaniline. The band is observed at $3,434 \mathrm{~cm}^{-1}$ at N-H stretching of aromatic rings. The main signal at $1670 \mathrm{~cm}^{-1}$ can be ascribed to the stretching of the carbonyl group and four distinct peaks with different intensities from 1450 to 1600 $\mathrm{cm}^{-1}$ are due to quinine skeletal stretching vibrations, respectively. The absorptions at 1592 and $1581 \mathrm{~cm}^{-1}$ are assigned to the stretching vibration of the $\mathrm{C}=\mathrm{C}$ bond in the aromatic ring (Li et al., 2008; Tan and Arof, 2006).

The peaks near 3400 and $2751 \mathrm{~cm}^{-1}$ indicate the presence of $\mathrm{OH}$ and $\mathrm{O}-\mathrm{C}-\mathrm{O}$ residues probably due to atmospheric moisture and carbon respectively. The appearance of the band near $1400-1530 \mathrm{~cm}^{-1}$ are assigned to the $\mathrm{C}=\mathrm{O}$ stretching of carbon surface. The absorption peak around 551 and $459 \mathrm{~cm}^{-1}$ can be attributed to the presence of strontium iron oxide phase. The strong absorption band arising at $551 \mathrm{~cm}^{-1}$ represents the bonding between Sr-o-Fe. The characteristic absorption at 735 and $924 \mathrm{~cm}^{-1}$ may be due to the possibility of co-FeOOH.

\section{$X R D$}

The XRD results of catalytic Ink Perovskite/polyaniline composites are shown in Fig. 4. The composite powder annealed at $900^{\circ} \mathrm{C}$ for $2 \mathrm{~h}$ shows a single phase, as observed from Fig. 4. This can be 
indexed to a single rhombohedral crystal structure with standard R-3C symmetry. The polyaniline shows two broad diffraction peaks at $2 \theta=39.5^{\circ}$ and $32.5^{\circ}$ as shown in Fig. 4., which can be assigned to the scattering from periodicity parallel and perpendicular molecule chains. By the in situ polymerization method, those perovskite composite can be incorporated in the polyaniline composites. According to the XRD patterns, it is found that the crystal structure is nothing changed in the catalytic Ink-perovskite/ polyethylene composites, but changed in the peak intensities. X-ray patterns clearly suggesting the formation of a highly crystallized powder. For these samples, X-ray diffraction patterns showed peaks at $2 \theta=32.4^{\circ}, 46.7^{\circ}$ and $58.1^{\circ}$ which were attributed to the perovskite structure (Singh et al., 2013; Silva et al., 2010). All perovskite structure peaks identificated were indexed as rhombohedral system.

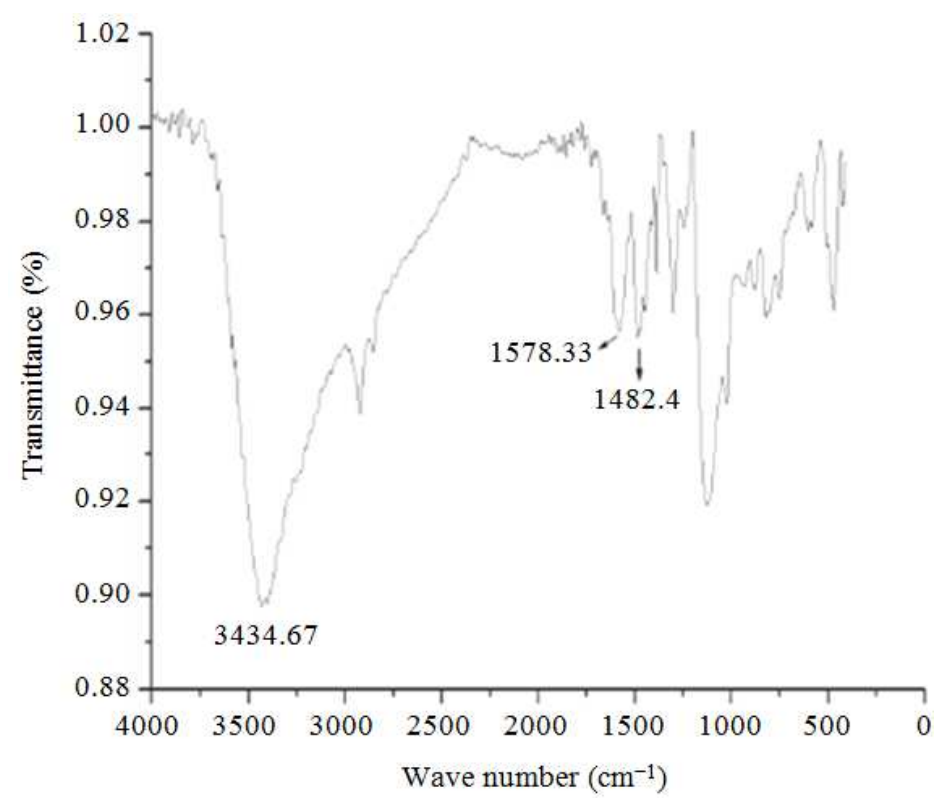

Fig. 3. FT-IR of Ink-perovskite/polyaniline composite electrode

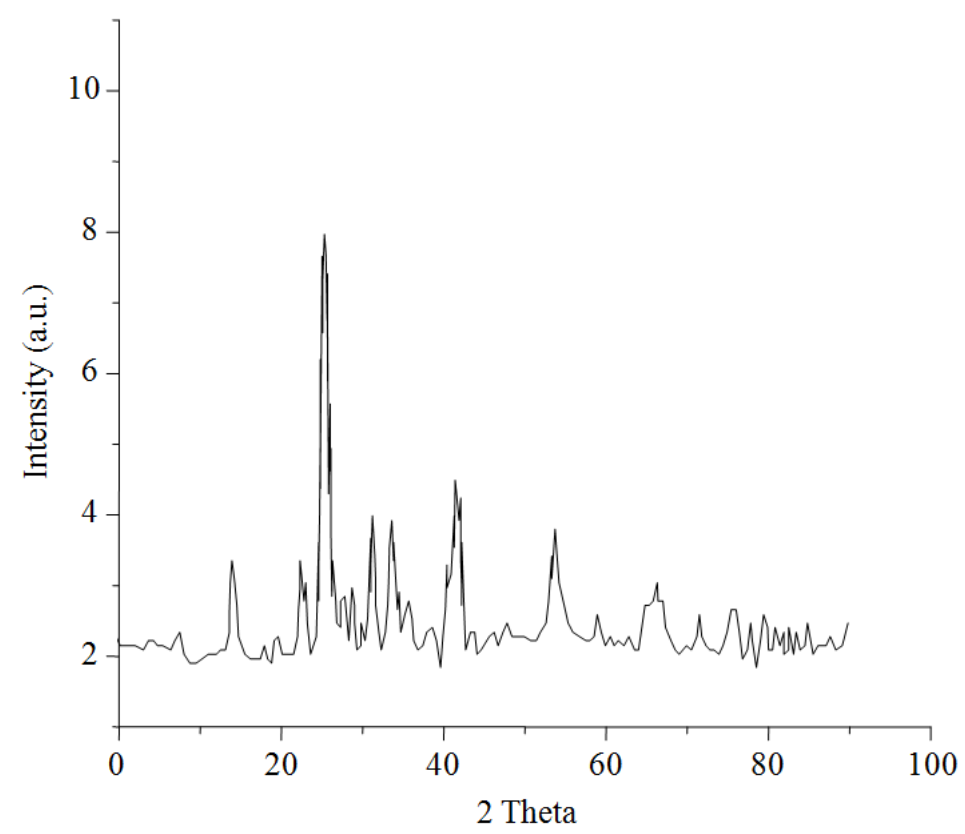

Fig. 4. XRD results of catalytic Ink Perovskite/polyaniline composites 


\section{$T G A$}

Thermal gravimetric analysis has been found to yield information on the decomposition temperatures of oxides as also about its thermal stability. Thermo gravimetric curves of the composite heated treated at $900^{\circ} \mathrm{C}$ and shown in Fig. 5. TGA curves showed an initial mass loss of about $21 \%$ in the temperature range of $30-315^{\circ} \mathrm{C}$ that is attributed to water loss, polyaniline initial decomposition and composite/polyaniline decompositions. A second loss weight of $39 \%$ can be observed in the range 315 $540^{\circ} \mathrm{C}$ which is due EDTA decomposition given perovskite oxide, sodium carbonate and sodium oxide. The TGA curve of ternary composite is show in the Fig. 5. The curves shown typically four regions of mass loss in the temperature range studied. EDTA thermo decomposition starting at $30^{\circ} \mathrm{C}$ and following until $750^{\circ} \mathrm{C}$. In the temperature range of $750-850^{\circ} \mathrm{C}$ there is the formation of a stable product that was attributed to strontium oxide/or Fe oxide. TGA curves of the EDTA residue obtained by calcinations at $773^{\circ} \mathrm{C}$ for $2 \mathrm{~h}$ showed an initial mass loss of about $9 \%$ in the temperature range of $80-108^{\circ} \mathrm{C}$ that was attributed to water loss. A second loss weight of about $90 \%$ in the temperature range of $860-1200^{\circ} \mathrm{C}$ was attributed to the decomposition of sodium carbonate, revealing the predominant presence of this material in the temperature range of 750 at $860^{\circ} \mathrm{C}$. For the samples heated treated at $220^{\circ} \mathrm{C}$, the complexation of nickel or cobalt. The mass loss observed between 30 $140^{\circ} \mathrm{C}$ was attributed to several simultaneous decomposition reactions of the residual material of the synthesis process. The samples still showed another decomposition step above $850^{\circ} \mathrm{C}$ which can be attributed to the decomposition of perovskite compounds.

\section{SEM}

The morphology of composite catalytic Inkperovskite/polyaniline was examined by HR SEM as shown in Fig. 6. It can be seen that composite display a gradual chain like structure of catalytic Inkperovskite/polyaniline. The formation of granular chain like structure could be understood as follows the polymerization of aniline was induced in a highly acidic condition and anilium ions adsorb readily on the surface of dispersed polyaniline composite and undergooxidativ polymerization. During polymerization the mutual repulsive interaction occurs between positively charged amine groups in polymer chain which in hence the free energy of the system is more likely to attain the stability by delocalization of the charge alone the alternative benginoid ring and amino group with flat configuration the zigzag configuration of aromatic ring possesses maximum conjugation and p-p stacking interaction in this way the whole system progress toward an internal chain structure (Silva et al., 2010). The chain like morphology has some influence electrical conductivity and electrochemical properties. That has catalytic ink/PANI granular structure in these blends and polyaniline is well dispersed in the Composite matrix. SEM micrographs showed non-uniform particles with sizes ranging from 2 to $20 \mu \mathrm{m}$. Such distribution in particle size may be a metal element which attributed to the preparation method and calcination temperature range used. The blunt, non uniform surface is the carbon (ink) surface.

\section{Electrical Conductivity}

The electrical conductivity of Inkperovskite/polyaniline was measured using a standard two probe method at room temperature. For the resultant Ink-perovskite/polyaniline composites show the highest conductivity of $128 \mathrm{Scm}^{-1}$. Electrical Conductivity depends on dimension as it is directly proportional to cross-sectional area and inversely proportional to the length of the composites. The granular chain like polymer shows the highest conductivity due to the morphology. The Conductivity of ternary composite increases with increasing the ratio of perovskite/polyaniline and vice versa. In the present study, the dependence of the conductivity of ternary composites on temperature were systematically investigated ( $\mathrm{Yu}$ et al., 2014). Figure 7 shows the conductivities of the ceramic samples in $30-80^{\circ} \mathrm{C}$ in the air. It can be seen from Fig. 7 that the overall conductivities of the samples increase with increasing temperature. The variation order in the conductivity may be explained by the mean activation energy of the conductivity. The high conductivity is observed for Inkperovskite/polyaniline to be $128 \mathrm{Scm}^{-1}$ at $80^{\circ} \mathrm{C}$.

Figure 8 represents the cyclic Voltammetry of Inkperovskite/polyanilineternary composite. The cyclic Voltammetry has been performed for the SS/Polymer electrolyte/SS cell couple with a scan rate of $10 \mathrm{~V} / \mathrm{s}$. The electrochemical window has been obtained from -0.2 to $+1.0 \mathrm{~V}$ for composite material. One peak observed at $0.21 \mathrm{~V}$ represents a slight degradation reaction of polyaniline.

The cathodic and anodic peaks of the cell are not observed. This may be due to non-interaction of metals in the polymer electrolyte with the SS electrodes. The cyclic voltammograms exhibit firmly about the cyclability and reversibility of electrolyte. 


\section{Electro Dialysis Process of Sodium Chloride}

The production of chlorine and caustic soda by electrolysis of aqueous solutions of sodium chloride is one of the most important electrochemical processes, demanding high energy consumption (Kiros and Bursell, 2008). In Chlor-alkali electrolysis is an aqueous solution of sodium chloride is decomposed electrolytic ally by direct current, producing chlorine at the anode, hydrogen at the cathode and sodium hydroxide solution in the catholyte chamber. So that the suitable cathode material define in the term of low power consumption and high current efficiency of the electrolysis process of sodium chloride (Riegel and Kent, 2003).

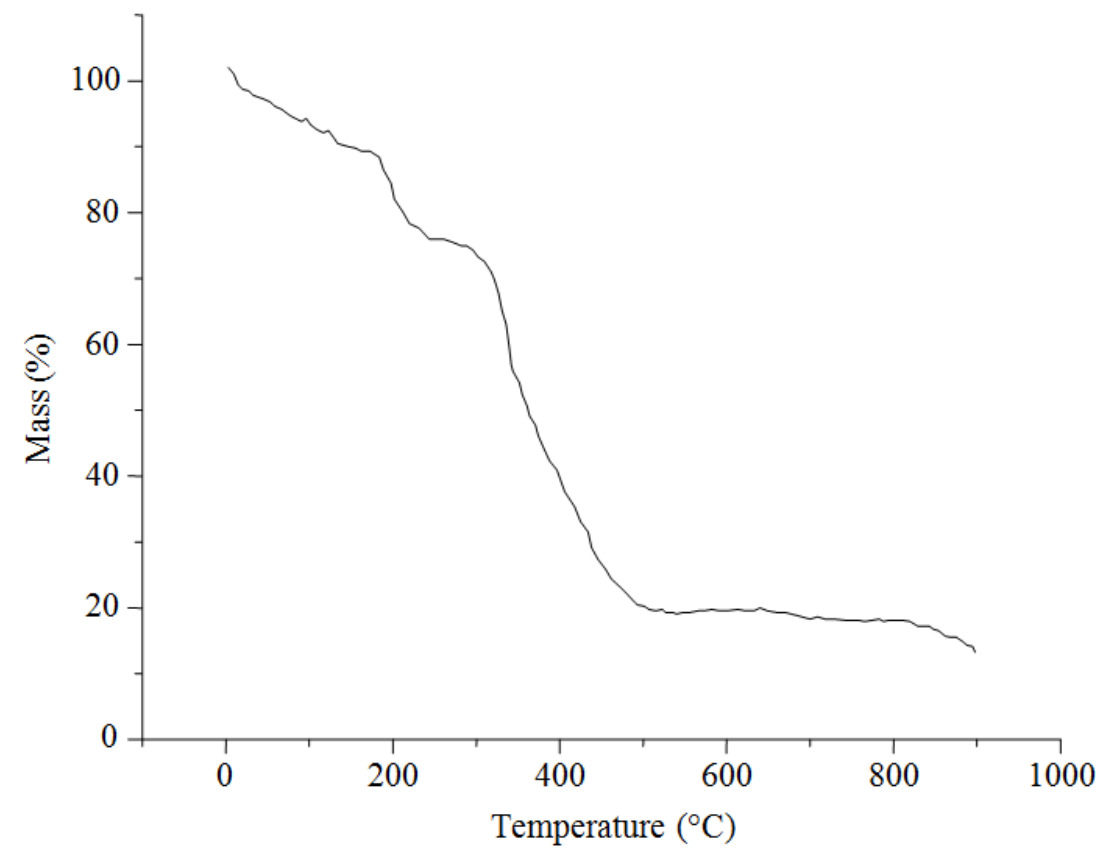

Fig. 5. Thermo gravimetric curves of the composite electrode

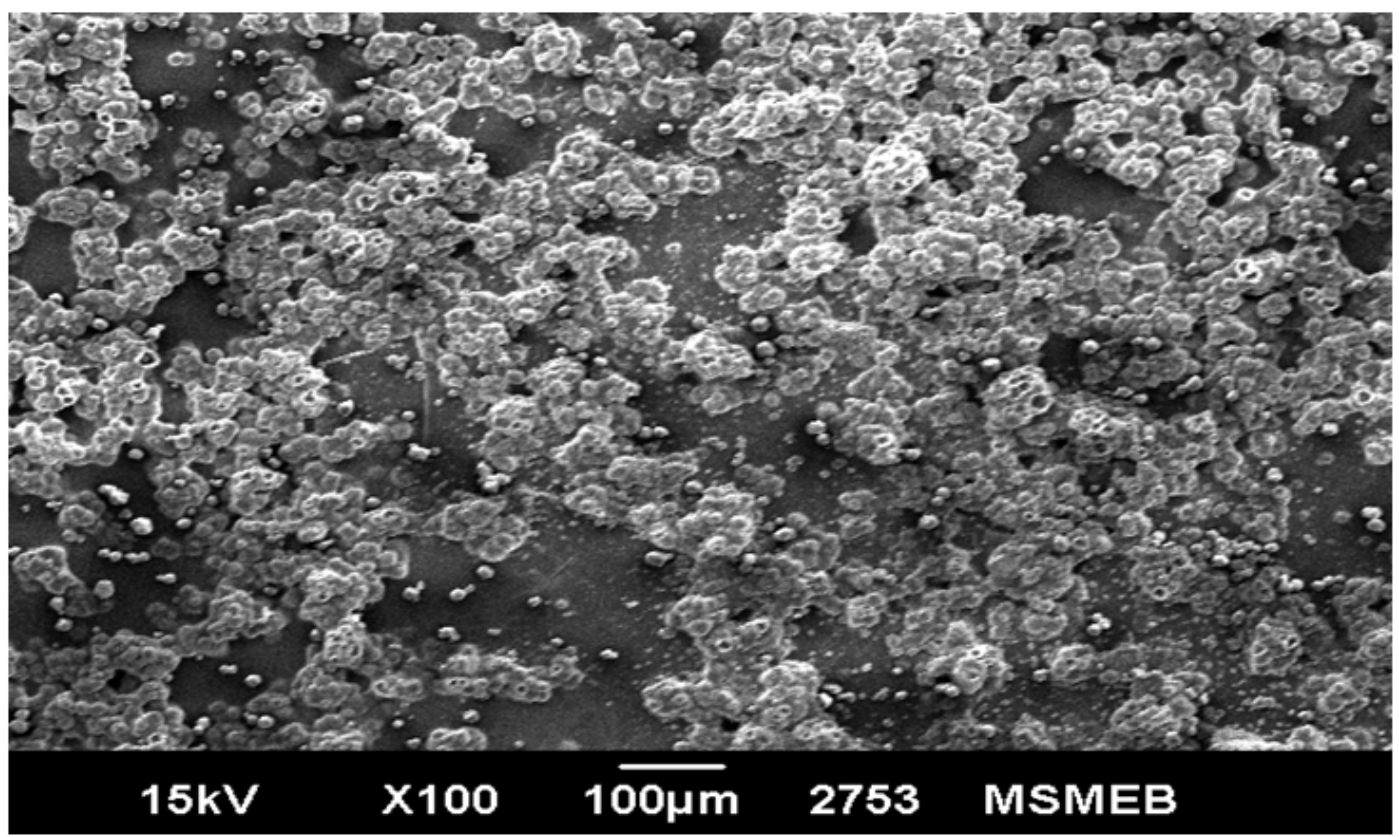

Fig. 6. SEM image of Ink-perovskite/polyaniline composite electrode 


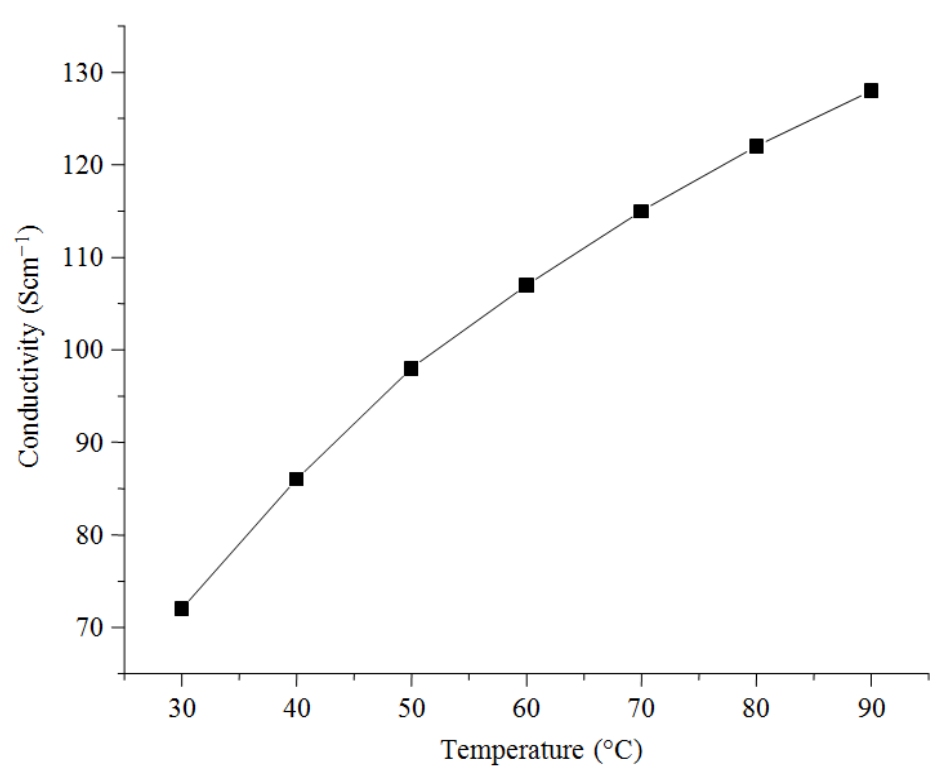

Fig. 7. Electrical conductivity of Ink-perovskite/polyaniline ternary composite

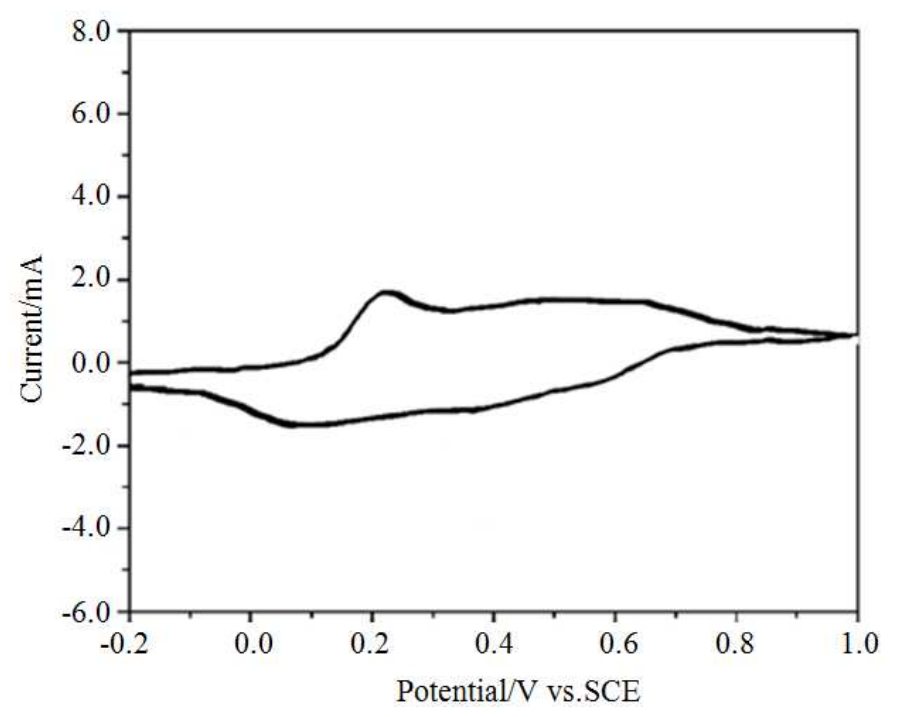

Fig. 8. Cyclic Voltammetry curve of electrode material

\section{Experimental Set up for Electrolysis}

The schematic of the apparatus used for the electrolysis experiments is illustrated in Fig. 9. It consists of two detachable compartments, each having a volume of $75 \mathrm{~mL}$ with the provision for fixing a membrane (Nafion ${ }^{\circledR}$ commercial membrane) (Pawlak et al., 2012) between the compartments. The inlets are connected to a peristaltic pump for the continuous flow of the electrolytic salutation. The two electrodes used, namely the cathode are made of stainless steel (reference electrode) and the anode is made of platinum (reference electrode) wire. The two salutation anolyte $(\mathrm{NaCl})$ and catholyte (water) are circulating through two, 1 liter glass reservoirs using peristaltic pumps. The salutation is continuously stirred with magnetic stirrers and the power is supplied using constant DC source. A potential difference is applied across the electrodes and a constant current density (254 $\mathrm{A} / \mathrm{m}^{2}$ ) through the membrane is maintained. Sample of catalyst is taken for $30 \mathrm{~min}$ time interval and the concentration of $\mathrm{NaOH}$ produced are measured volumetrically by the titration method. The current efficiency (\%) and the power consumed $(\mathrm{kWh} / \mathrm{mol} \mathrm{NaOH}$ produced) are determined by the following formulae:

$$
\eta=\frac{\Delta C \cdot v}{I \cdot \Delta t / F} \times 100
$$




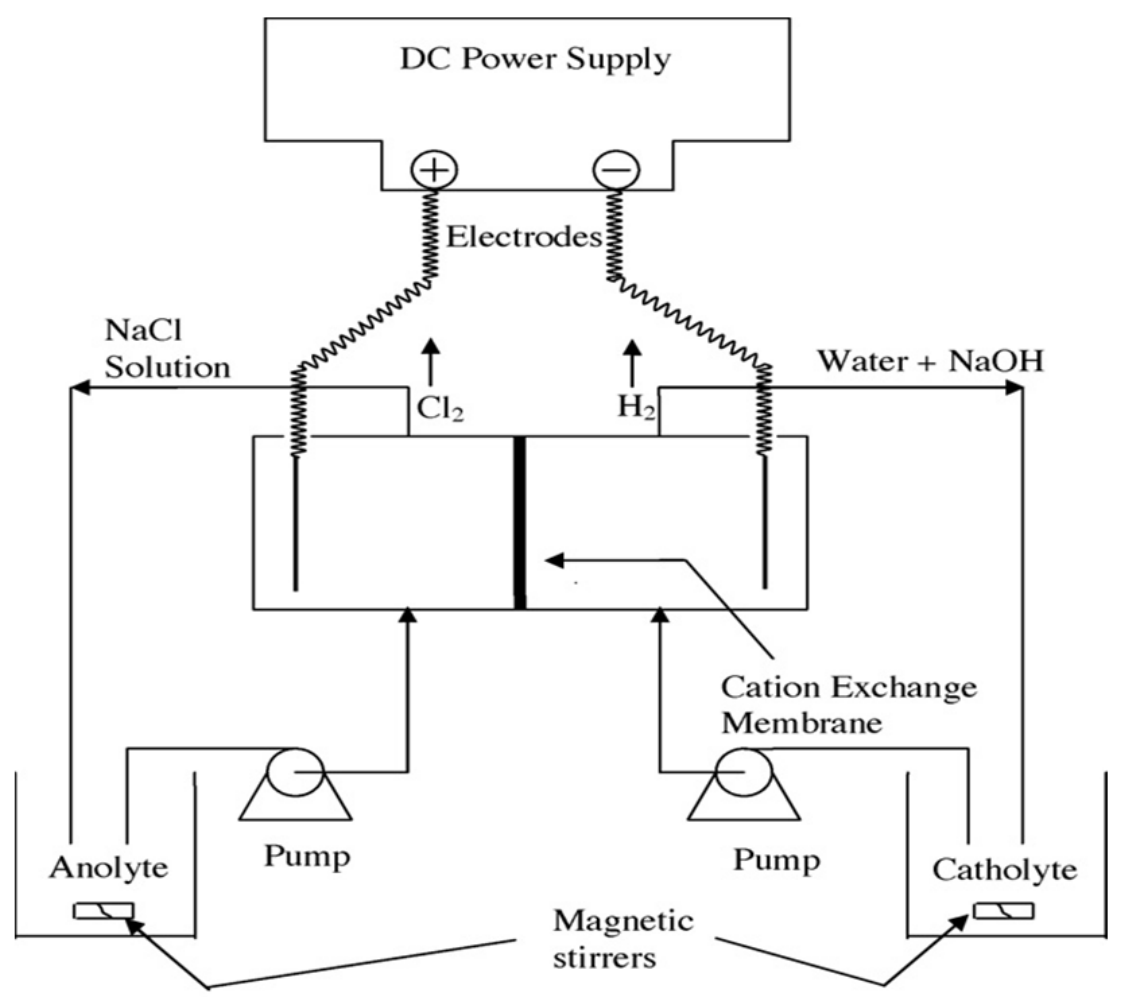

Fig. 9. Electro dialysis experiment setup

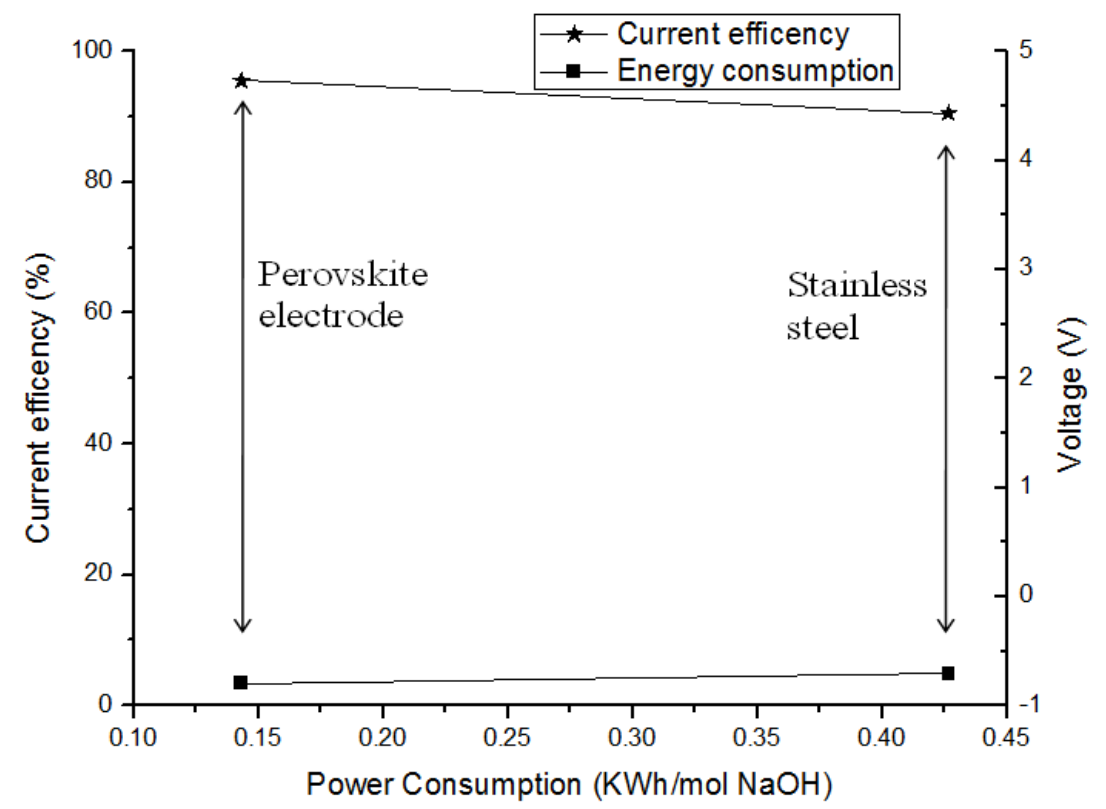

Fig. 10. Power consumption and current efficiency of different electrode

Table 1. Power consumption, current efficiency and voltage of perovskite electrode

\begin{tabular}{llll}
\hline Electrode & Voltage (V) & Current efficiency (\%) & $\begin{array}{l}\text { Power consumption (KWh/mol } \\
\text { of NaOH production) }\end{array}$ \\
\hline Stainless steel & 4.9 & 90.5 & 0.4268 \\
Perovskite composite & 3.4 & 95.4 & 0.1462 \\
\hline
\end{tabular}


$\mathrm{NaOH} \mathrm{kWh} / \mathrm{mol}$ of produced:

$$
E=\frac{V_{A v g} \cdot I \cdot t}{\Delta N \cdot 1000} E=\frac{V_{A v g} \cdot I \cdot t}{\Delta N \cdot 1000}
$$

Where:

$\Delta C=$ The change in concentration of $\mathrm{NaOH}$ (mol/lit) in time $\Delta t$ seconds

$\mathrm{v}=$ The volume of catholyte solution in liter, $I$ is the current in amperes

$F=$ The Faradays' number, $\mathrm{V}_{A v g}$ is the average cell voltage for each electro dialysis run

$\Delta N=$ The moles of $\mathrm{NaOH}$ produced during the electrolysis run for time $t$

Table 1 shows the power consumption, current efficiency and voltage of perovskite electrode with respect of reference electrode (SS) for the electro dialysis of Sodium chloride.

Figure 10, defines that the perovskite composite electrode consumes low energy and produce highest current efficiency comparatively to the stainless steel electrode with respect of low voltage drop. The highest Electrical Conductivity of perovskite composite materials denote by the term of highest ionic motion of the ions and more activation energy also, due to that oxygen reduction reaction consumes low power.

\section{Conclusion}

In this study, we have synthesized inkperovskite/polyaniline ternary composite electrode for sodium chloride separation process and investigated its structure, morphology and electrochemical properties. We observed the conducting material shows maximum conductivity $128 \mathrm{Scm}^{-1}$ at $80^{\circ} \mathrm{C}$. The FT-IR study shows functional groups presents in the material and the X-ray diffraction defined the molecular structure of the composites.

SEM images show the polymerization dispersion of different particles of Polyaniline on carbon surface. TGA analysis confirms the material is stable up to $800^{\circ} \mathrm{C}$. We also study the Cyclic Voltammetry to explain electrochemical properties of the materials. The electrodialysis experiment result of perovskitr/polyaniline ternary composite material shows the best result comparatively stainless steel electrode material. According to this we can easily replace Stainless steel electrode by a peroveskite composite electrode. These all result prove that the ternary composite is economical, eco-friendly and suitable cathode material which reduces required power consumption of sodium chloride separation.

\section{Author's Contributions}

Savita Dixit: All experiments were conducted under her supervisor. She did all proof reading.

Sandhya Pal: She conducted the experiments and results placed in order final she has written the manuscript for publication.

\section{Ethics}

This article is original and contains unpublished material. The corresponding author confirms that all of the other authors have read and approved the manuscript and no ethical issues involved.

\section{References}

Adams, P.N., P.J. Laughlin, A.P. Monkman and A.M. Kenwright, 1996. Low temperature synthesis of high molecular weight polyaniline. Polymer, 37: 3411-3417. DOI: 10.1016/0032-3861(96)88489-8

Ahmed, M.I., H.T. Chang, J.R. Selman and T.M. Holsen, 2002. Electrochemical chromic acid regeneration process: Fitting of membrane transport properties. J. Membr. Sci., 197: 63-74.

DOI: $10.1016 / \mathrm{S} 0376-7388(01) 00596-8$

Bastidas, D.M., S. Tao and J.T.S. Irvine, 2006. A symmetrical solid oxide fuel cell demonstrating redox stable perovskite electrodes. J. Mater. Chem., 16: 1603-1605. DOI: 10.1039/B600532B

Bazinet, L., 2004. Electrodialytic phenomena and their applications in the dairy industry: A review. Crit. Rev. Food Sci. Nutr., 44: 525-544. DOI: $10.1080 / 10408690490489279 a$

Bezerra, C.W.B., L. Zhang, K. Lee, H. Liu and A.L.B. Marques et al., 2008. A review of $\mathrm{Fe}-\mathrm{N} / \mathrm{C}$ and Co$\mathrm{N} / \mathrm{C}$ catalysts for the oxygen reduction reaction. Electrochim. Acta, 53: 4937-4951. DOI: $10.1016 /$ j.electacta.2008.02.012

Cui, K., Y. Cheng, J. Dai and J. Liu, 2013. Synthesis, characterization and microwave absorption properties of $\mathrm{La}_{0.6} \mathrm{Sr}_{0.4} \mathrm{MnO}_{3} /$ polyaniline composite. Mater. Chem. Phys., 138: 810-816.

DOI: 10.1016/j.matchemphys.2012.12.064

Faubert, G., R. Cote, D. Guay, J.P. Dodelet and G. Denes et al., 1998. Activation and characterization of Febased catalysts for the reduction of oxygen in polymer electrolyte fuel cells. Electrochim. Acta, 43: 1969-1984. DOI: 10.1016/S0013-4686(97)10120-7

Faverjon, F., G. Durand and M. Rakib, 2006. Regeneration of hydrochloric acid and sodium hydroxide from purified sodium chloride by membrane electrolysis using a hydrogen diffusion anode-membrane assembly. J. Membr. Sci., 284: 323-330. DOI: 10.1016/j.memsci.2006.07.051 
Furuya, N. and H. Aikawa, 2000. Comparative study of oxygen cathodes loaded with $\mathrm{Ag}$ and Pt catalysts in chlor-alkali membrane cells. Electrochim. Acta, 45: 4251-4256. DOI: 10.1016/S0013-4686(00)00557-0

Huang, C., T. Xu, Y. Zhang, Y. Xue and G. Chen, 2007. Application of electrodialysis to the production of organic acids: state-of-the-art and recent developments. J. Membr. Sci., 288: 1-12.

DOI: 10.1016/j.memsci.2006.11.026

Kalogirou, S.A., 2005. Seawater desalination using renewable energy sources. Prog. Energy Combust. Sci., 31: 242-281. DOI: 10.1016/j.pecs.2005.03.001

Kariduraganavar, M.Y., R.K. Nagarale, A.A. Kittur and S.S. Kulkarni, 2006. Ion-exchange membranes: preparative methods for electrodialysis and fuel cell applications. Desalination, 197: 225-246.

DOI: 10.1016/j.desal.2006.01.019

Kharton, V.V., A.A. Yaremchenko, A.V. Kovalevsky, A.P. Viskup and E.N. Naumovich et al., 1999. Perovskite-type oxides for high-temperature oxygen separation membranes. J. Membr. Sci., 163: 307-317. DOI: $10.1016 / \mathrm{S} 0376-7388(99) 00172-6$

Kiros, Y. and M. Bursell, 2008. Low energy consumption in chlor-alkali cells using oxygen reduction electrodes. Int. J. Electrochem. Sci., 3: 444-451.

Li, X.G., A. Li and M.R. Huang, 2008. Facile high-yield synthesis of polyaniline nanosticks with intrinsic stability and electrical conductivity. Chem. Eur. J., 14: 10309-10317. DOI: 10.1002/chem.200801025

Lurdes, M., F. Ciriaco, I.M. Da, S.P. Manuel and R. Nunes et al., 2001. Preparation and characterization of $\mathrm{KTa}_{0.9} \mathrm{Fe}_{0.1} \mathrm{O}_{3-\delta}$ perovskite electrodes. J. Solid State Electrochem., 5: 495-501. DOI: $10.1007 / \mathrm{s} 100080100227$

Matthew, S. and S. Swartz, 2004. Perovskite electrodes and method of making the same.

Noble, R.D. and S.A. Stern, 1995. Membrane Separations Technology: Principles and Applications. 1st Edn., Elsevier, New York, ISBN-10: 0080536182, pp: 738.

Ogura, K., H. Shiigi, M. Nakayama and A. Fujii, 1998. Thermogravimetric/Mass and infrared spectroscopic properties and humidity sensitivity of polyaniline derivatives/polyvinyl alcohol composites. J. Electrochem. Soc., 145: 3351-3357.

DOI: $10.1149 / 1.1838811$

Pawlak, E.G., M. Sohail, M. Pawlak, B. Neel and A. Shvarev et al., 2012. Coulometric sodium chloride removal system with nafion membrane for seawater sample treatment. Anal. Chem., 84: 6158-6165. DOI: $10.1021 / \mathrm{ac} 301096 \mathrm{r}$
Phadnis, A.M. and V.K. Joshi, 2007. Chemical industry digest.

Riegel, E.R. and J.A. Kent, 2003. Riegel's Handbook of Industrial Chemistry. 1st Edn., Springer Science and Business Media, New York, ISBN-10: 0306474115, pp: 1373.

Santarosa, V.E., F. Peretti, V. Caldart, J. Zoppas and M. Zeni, 2002. Study of ion-selective membranes from electrodialysis removal of industrial effluent metals II: Zn and Ni. Desalination, 149: 389-391. DOI: $10.1016 / \mathrm{S} 0011-9164(02) 00848-2$

Sarraco, G., 2003. Ionic membrane technologies for the recovery of valuable chemicals from waste waters. Ann. Chim., 93: 817-826. PMID: 14672375

Silva, G.R.O., J.C. Santos, D.M.H. Martinelli, A.M.G. Pedrosa and M.J.B. de Souza et al., 2010. Synthesis and characterization of LaNixCo1-xO3 perovskites via complex precursor methods. Mater. Sci. Applic., 1: 39-45. DOI: 10.4236/msa.2010.12008

Singh, S., A. Singh, B.C. Yadav and P.K. Dwivedi, 2013. Fabrication of nanobeads structured perovskite type neodymium iron oxide film: Its structural, optical, electrical and LPG sensing investigations. Sensors Actuat. B, 177: 730-739. DOI: 10.1016/j.snb.2012.11.096

Strathmann, H., 2004. Ion-Exchange Membrane Separation Processes. 1st Edn., Elsevier, Amsterdam, ISBN-10: 0080509401, pp: 360.

Strathmann, H., 2005. Membranes and Membrane Separation Processes. In: Ullmann's Encyclopedia of Industrial Chemistry, pp: 209-258.

Tan, W. and A.K. Arof, 2006. FT-IR studies on interactions among components in hexanoyl chitosan-based polymer electrolytes. Spectrochim. Acta, 63: 677-684. DOI: 10.1016/j.saa.2005.06.018

Tongwen, X., 2002. Electrodialysis processes with Bipolar Membranes (EDBM) in environmental protection-a review. Resour. Conserv. Recycl., 37: 1-22. DOI: 10.1016/S0921-3449(02)00032-0

Tributsch, H., U.I. Koslowski and I. Dorbandt, 2008. Experimental and theoretical modeling of Fe-, Co-, $\mathrm{Cu}-, \mathrm{Mn}$-based electrocatalysts for oxygen reduction. Electrochim. Acta, 53: 2198-2209. DOI: $10.1016 /$ j.electacta.2007.09.027

Tsiakaras, P., C. Athanasiou, G. Marnellos, M. Stoukides and J.E. Ten Elsoff et al., 1998. Methane activation on a $\mathrm{La}_{0.6} \mathrm{Sr}_{0.4} \mathrm{Co}_{0.8} \mathrm{Fe}_{0.2} \mathrm{O}_{3}$ perovskite: Catalytic and electrocatalytic results. Appl. Catal. A: Gen., 169: 249-261. DOI: 10.1016/S0926-860X(98)00013-1

Wang, B., 2005. Recent development of non-platinum catalysts for oxygen reduction Reaction. J. Power Sour., 152: 1-15.

DOI: 10.1016/j.jpowsour.2005.05.098 
Wang, H., R. Wang, D.T. Liang and W. Yang, 2004. Experimental and modeling studies on $\mathrm{Ba}_{0.5} \mathrm{Sr}_{0.5} \mathrm{Co}_{0.8} \mathrm{Fe}_{0.2} \mathrm{O}_{3-\delta} \quad$ (BSCF) tubular membranes for air separation. J. Membr. Sci., 243: 405-415.

DOI: $10.1016 /$ j.memsci.2004.07.003

Ye, S. and A.K. Vijh, 2003. Non-noble metalcarbonized aerogel composites as electrocatalysts for the oxygen reduction reaction. Electrochem. Commun., 5: 272-275.

DOI: $10.1016 / \mathrm{S} 1388-2481(03) 00043-2$
Yu, T., X. Mao and G. Ma, 2014. Performance of cobaltfree perovskite $\mathrm{La}_{0.6} \mathrm{Sr}_{0.4} \mathrm{Fe}_{1-\mathrm{x}} \mathrm{NbxO}_{3-\delta}$ cathode materials for proton-conducting IT-SOFC. J. Alloys Compounds, 608: 30-34.

DOI: $10.1016 /$ j.jallcom.2014.04.071

Zhong, H., H. Zhang, G. Liu, Y. Liang and J. Hu et al., 2006. A novel non-noble electrocatalyst for PEM fuel cell based on molybdenum nitride. Electrochem. Commun., 8: 707-712. DOI: $10.1016 /$ j.elecom.2006.02.020 